\title{
Malignant arrhythmia associated with mitral annular disjunction: Myocardial work as a potential tool in the search for a substrate
}

\author{
Krzysztof Jaworski', Bohdan Firek', Paweł Syska², Michał Lewandowski ${ }^{2}$, Mateusz Śpiewak ${ }^{3}$, Rafał Dąbrowski ${ }^{1}$
}

\author{
'Department of Coronary Artery Disease and Cardiac Rehabilitation, National Institute of Cardiology, Warszawa, Poland \\ ${ }^{2} 2^{\text {nd }}$ Department of Arrhythmia, National Institute of Cardiology, Warszawa, Poland \\ ${ }^{3}$ Magnetic Resonance Unit, Department of Radiology, National Institute of Cardiology, Warszawa, Poland
}

\author{
Correspondence to: \\ Krzysztof Jaworski, MD, \\ Department of Coronary \\ Artery Disease and Cardiac \\ Rehabilitation, \\ National Institute of Cardiology, \\ Alpejska 42, 04-628 Warszawa, \\ Poland \\ phone: +482234342 59, \\ e-mail: kjaworski@ikard.pl \\ Copyright by the Author(s), 2022 \\ DOI: 10.33963/KP.a2021.0127 \\ Received: \\ August 27, 2021 \\ Accepted: \\ October 7, 2021 \\ Early publication date: \\ October 7, 2021
}

A 28-year-old woman with no history of cardi-
ovascular disease survived witnessed sudden
cardiac arrest, which happened at rest. She
was successfully resuscitated and did not pres-
ent any neurological deficit. The family history
regarding sudden cardiac death was negative. The electrocardiogram showed no abnormalities specific for channelopathies. Transthoracic echocardiography revealed mitral valve prolapse with insignificant regurgitation, the morphology and function of both ventricles were normal. Cardiac magnetic resonance detected neither late gadolinium enhancement nor other features of structural heart disease. Coronary arteries were normal as assessed on computed tomography angiography. The patient underwent implantation of a subcutaneous cardioverter-defibrillator.

Two years later, she was admitted to our hospital due to ventricular fibrillation terminated by the device shock. The electrocardiogram (ECG) presented no relevant changes, the corrected QT interval was $444 \mathrm{~ms}$ (Figure 1A). The 24-hour ECG monitoring revealed premature ventricular complexes of several morphology and non-sustained ventricular tachycardia (Figure 1B). This arrhythmia was also induced during the treadmill exercise test, especially in the recovery phase. On echocardiography, the only pathological findings were left atrial dilation, mitral valve prolapse associated with mitral annular disjunction, mild mitral regurgitation, and considerable tugging of papillary muscles (Figure 1C; Supplementary material, Video S1). Pickelhaube sign (high, spiked systolic velocity profile resembling a German military helmet) was evident on tissue Doppler imaging
(Figure 1D). The analysis of myocardial work (MW) demonstrated an increased MW index in the inferolateral wall of the left ventricle (Figure 1E, F). The therapy with $\beta$-blocker was intensified. In over a one-year follow-up, no interventions of subcutaneous cardioverter-defibrillator were observed.

Mitral valve prolapse occurs in $2 \%-3 \%$ of the general population [1]. In most cases, it is a benign entity, but rarely it may be associated with malignant ventricular arrhythmias. The main risk factors include leaflet thickness $>5 \mathrm{~mm}$, bileaflet prolapse, papillary muscle fibrosis, and mitral annular disjunction [1, 2]. Zienciuk-Krajka et al. [3] recently reported that among patients with arrhythmic mitral valve prolapse, survivors of cardiac arrest had a higher E/e' ratio. Myocardial work represents a relatively new echocardiographic parameter. Owing to the combination of speckle tracking technique assessing longitudinal strain and blood pressure measurements, it reflects global as well as regional left ventricular work [4]. The application of this method provided insight into the possible substrate for arrhythmia in the presented patient. Excessive local contraction and stretch of cardiomyocytes may predispose to premature depolarization and trigger ventricular tachycardia or fibrillation via the $\mathrm{R} / \mathrm{T}$ phenomenon $[2,5]$. Further studies are needed to evaluate the diagnostic and prognostic value of MW in patients with mitral valve prolapse.

\section{Supplementary material}

Supplementary material is available at https:// journals.viamedica.pl/kardiologia_polska. 

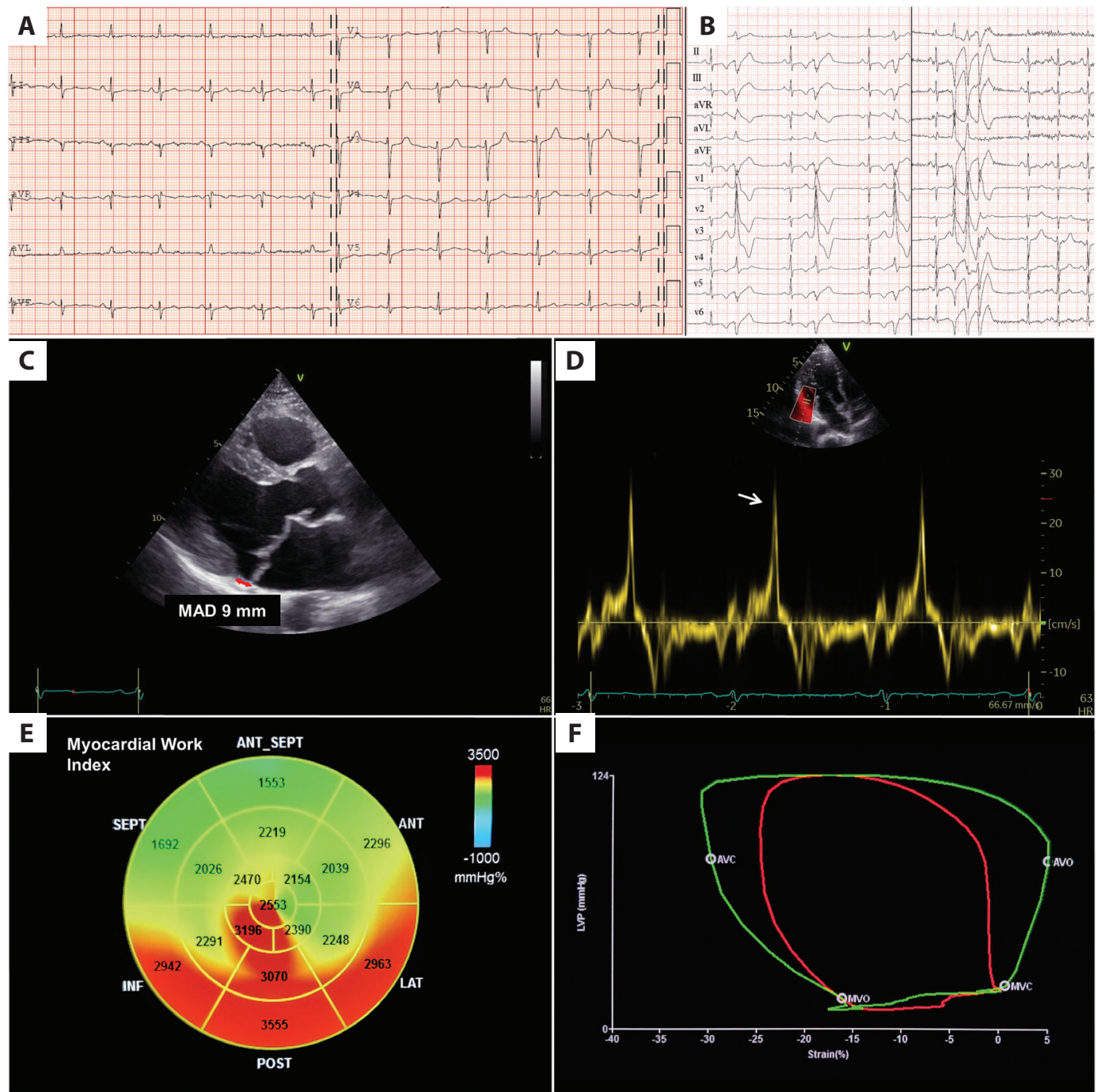

Figure 1. A. The electrocardiogram shows no relevant abnormalities. B. Holter electrocardiogram recording showing premature ventricular complexes and non-sustained ventricular tachycardia. C, D. The transthoracic echocardiogram presents mitral annular disjunction on 2D (the red double arrow) and Pickelhaube sign on tissue Doppler imaging (the white arrow). E, F. Myocardial work analysis demonstrates a significantly increased MW index in the inferolateral wall of the left ventricle depicted as bull's-eye plot and pressure-strain loop of the basal segment (green — basal posterior, red — average, blood pressure - 124/72 $\mathrm{mm} \mathrm{Hg}$ )

Abbreviations: MAD, mitral annular disjunction; MW, myocardial work

\section{Article information}

Conflict of interest: None declared.

Open access: This article is available in open access under Creative Common Attribution-Non-Commercial-No Derivatives 4.0 International (CC BY-NC-ND 4.0) license, allowing to download articles and share them with others as long as they credit the authors and the publisher, but without permission to change them in any way or use them commercially. For commercial use, please contact the journal office at kardiologiapolska@ptkardio.pl.

\section{REFERENCES}

1. Dejgaard LA, Skjølsvik ET, Lie ØH, et al. The mitral annulus disjunction arrhythmic syndrome. J Am Coll Cardiol. 2018; 72(14): 1600-1609, doi: 10.1016/j.jacc.2018.07.070, indexed in Pubmed: 30261961.

2. Muthukumar L, Jahangir A, Jan MF, et al. Association between malignant mitral valve prolapse and sudden cardiac death: a review. JAMA Cardiol. 2020; 5(9): 1053-1061, doi: 10.1001/jamacardio.2020.1412, indexed in Pubmed: 32936277.

3. Zienciuk-Krajka A, Daniłowicz-Szymanowicz L, Dorniak K, et al. Clinical characteristics of patients with arrhythmic mitral valve prolapse in a single tertiary center: prevalence of electrocardiographic and myocardial abnormalities. Kardiol Pol. 2021; 79(6): 693-696, doi: 10.33963/KP.a2021.0008, indexed in Pubmed: 34013515.

4. Russell K, Eriksen M, Aaberge L, et al. A novel clinical method for quantification of regional left ventricular pressure-strain loop area: a non-invasive index of myocardial work. Eur Heart J. 2012; 33(6): 724-733, doi: 10.1093/eurheartj/ehs016, indexed in Pubmed: 22315346.

5. Franz MR, Cima R, Wang D, et al. Electrophysiological effects of myocardial stretch and mechanical determinants of stretch-activated arrhythmias. Circulation. 1992; 86(3): 968-978, doi: 10.1161/01.cir.86.3.968, indexed in Pubmed: 1381296. 